\title{
La crónica latinoamericana: cruce entre literatura, periodismo y análisis social
}

\author{
American chronicle: intersection of literature, journalism and social analysis
}

\author{
Adriana Callegaro ${ }^{1}$ \\ ( adricall16@hotmail.com) \\ María Cristina Lago ${ }^{2}$ \\ ( kittylago@yahoo.com.ar) \\ http://dx.doi.org/10.5216/cei.v15i1.22496
}

\begin{abstract}
Resumen
Uno de los objetivos de este trabajo ha sido abordar la crónica latinoamericana comparativamente con el registro clásico e identificar desplazamientos de sentido en torno a las representaciones de los sectores populares, respecto del tratamiento que tradicionalmente le otorga el periodismo hegemónico. Las crónicas que constituyen nuestro corpus revisten un interés particular pues refieren historias reales en un registro más cercano a lo literario que a lo periodístico, en el que la subjetividad del enunciador-cronista-narrador atraviesa las descripciones y los acontecimientos o bien introduce otras subjetividades. Las estrategias de objetividad dan paso a técnicas de ficcionalización que hacen emerger la subjetividad aún en el uso de la tercera persona. Se ha elegido, entonces, la metodología del análisis del discurso, en especial con instrumentos de la narratología. Para ello, se ha constituido un marco teórico instrumental desde el que se ha realizado el análisis en el que se articulan los aportes de Schaeffer (1999), Metz (1972), Eco (1996, Genette (1972) y Ricoeur (1978), entre otros.
\end{abstract}

Palabras-clave: Crónica Latinoamericana. Representaciones. Sectores Populares. Periodismo y Literatura.

\begin{abstract}
One objective of this work has been to address the chronic American classic comparatively with registration and identify meaning displacements around representations of popular sectors, regarding the treatment traditionally hegemonic journalism grants. The chronicles that constitute our corpus of particular interest because stories relate actual track closest thing to literary journalism, in which the subjectivity of the speaker-writer-narrator through the descriptions and events or enter other subjectivities, by choosing from multiple viewpoints. Objectivity strategies give way to making techniques fictionalization subjectivity emerge even in the use of the third person. This process causes a disruption fictionalization collective belief in mobilizing new looks that far from legitimizing the collective imaginary, establishing interpretive tensions. Is chosen, then the body deal with the methodology selected chronic discourse analysis, especially narratology instruments. For this, a theoretical framework has been instrumental from which the analysis was performed in which the contributions are articulated Schaeffer (1999), Metz (1972), Eco (1996, Genette (1972) and Ricoeur (1978), among others.
\end{abstract}

Keywords: Chronicle Latino Americana. Representations. Popular Sectors. Journalism and Literature.

$\begin{array}{ll}1 & \text { Universidad Nacional de La Matanza (UNLaM), Argentina, Buenos Aires. } \\ 2 & \text { Universidad Nacional de La Matanza (UNLaM), Argentina, Buenos Aires. }\end{array}$

Comum. \& Inf., v. 15, n.1, p. 46-65, jan./jun. 2012 


\section{Introducción}

Desde hace algunos años, la situación social latinoamericana es retratada con otro registro que se aleja del estrictamente informativo característico de la práctica periodística de las redacciones. La vida cotidiana de la gente común, y de los sectores marginados, así como la puesta en escena de prácticas de supervivencia y lucha de dichos sectores suelen ser los temas abordados por jóvenes cronistas para contar historias que conmueven, asombran e indignan, en un diálogo permanente con la literatura y el análisis sociocultural.

La crónica, en el periodismo hegemónico, recurre a estrategias diversas a los efectos de conceder a la exigencia de objetividad que pesa sobre ella. El uso de la tercera persona, la marcación pormenorizada de índices de tiempo y espacio, la mención de fuentes legitimadas son algunos de los recursos con los que dicha crónica canónica construye la ilusión de distanciamiento necesario respecto de lo narrado con el que pretende "asegurar" la credibilidad en el lector.

Las crónicas que constituyen nuestro corpus, en cambio, revisten un interés particular pues refieren historias reales en un registro más cercano a lo literario que a lo periodístico, en el que la subjetividad del enunciador-cronista-narrador tiñe descripciones y acontecimientos o bien da paso a la subjetividad de los protagonistas y actores de dichas historias, mediante la elección de puntos de vista múltiples que lejos de distanciarse de los acontecimientos, buscan poner de relieve la presencia de un enunciador periodístico involucrado afectivamente con lo narrado. Para ello, las estrategias de objetividad dan paso a técnicas de ficcionalizaciòn que hacen emerger la subjetividad aún en el uso de la tercera persona. Tampoco se presentan como historias totalizadoras ni cerradas. Por el contrario, importan por el detalle, materializado en fragmentos narrativos que operan como metonimia emocional. $\mathrm{Al}$ acentuar la focalización en un aspecto, escena o episodio aparentemente secundario, suscitan en el lector una serie de resonancias u operaciones de completamiento que se vinculan con sentimientos pathèmicos universales.

Por ello, provocan una disrupción en la creencia colectiva movilizando nuevas miradas que, lejos de legitimar el imaginario colectivo, instauran tensiones interpretativas. De ahí, su estatuto transgresor que altera la comodidad de las representaciones sociales instituidas por el periodismo hegemónico, pues abordan las tensiones sociales haciendo emerger el conflicto. 
La trasgresión a la estructura convencional (cronología lineal, pirámide invertida, copete resumen), como la alteración de las relaciones entre el tiempo de la historia y el tiempo del relato, convocan a un lector diferente vinculado a los nuevos soportes no convencionales (blogs, revistas literarias o de periodismo narrativo) por los que estas crónicas circulan.

El cuadro siguiente reúne las principales categorías mencionadas, que distinguen, comparativamente, la crónica tradicional de la nueva crónica:

\begin{tabular}{|c|c|}
\hline CRÒNICA HEGEMÒNICA & $\begin{array}{l}\text { NUEVA CRÒNICA } \\
\text { LATINOAMERICANA }\end{array}$ \\
\hline $\begin{array}{l}\text { - Mirada que busca la ilusión de } \\
\text { objetividad y la distancia. }\end{array}$ & $\begin{array}{l}\text { - Mirada subjetiva que busca } \\
\text { proximidad con el cronista. }\end{array}$ \\
\hline $\begin{array}{l}\text { - Interés noticioso por ricos, } \\
\begin{array}{l}\text { famosos, poderosos } \\
\text { contingente de la agenda. }\end{array}\end{array}$ & $\begin{array}{l}\text { - Interés por lo cotidiano, historias } \\
\text { mínimas de personajes anónimos. }\end{array}$ \\
\hline - Ambición por abarcar la totalidad. & $\begin{array}{l}\text { - No renuncia a la totalidad pero lo } \\
\text { hace a partir de los detalles y las } \\
\text { márgenes. }\end{array}$ \\
\hline $\begin{array}{l}\text { - Soportes tradicionales de la prensa } \\
\text { hegemónica. }\end{array}$ & $\begin{array}{l}\text { - Soportes no convencionales (blogs, } \\
\text { libros, revistas culturales. }\end{array}$ \\
\hline $\begin{array}{l}\text { - Fuentes autorizadas } \\
\text { funcionarios, policía, etc.) }\end{array}$ & $\begin{array}{l}\text { - Testigos, protagonistas dando } \\
\text { cuenta del hecho. }\end{array}$ \\
\hline $\begin{array}{l}\text { - } \begin{array}{l}\text { Construcción cronológica } \\
\text { relato alineado a la agenda (la } \\
\text { noticia mira al poder). }\end{array} \\
\end{array}$ & $\begin{array}{l}\text { - Técnicas de producción como el } \\
\text { montaje y el collage de imágenes. } \\
\text { Abordaje fragmentario. }\end{array}$ \\
\hline $\begin{array}{l}\text { - Cobertura del suceso ajustado a un } \\
\text { horario de cierre. Poco espacio. }\end{array}$ & $\begin{array}{l}\text { - Mayor extensión y trabajo de } \\
\text { campo de parte del cronista. }\end{array}$ \\
\hline $\begin{array}{l}\text { - Acopio de datos precisos para } \\
\text { lograr efecto de verosimilitud. }\end{array}$ & $\begin{array}{l}\text { - Desinterés por señales de } \\
\text { evidencialidad (cifras, nombres, } \\
\text { números). }\end{array}$ \\
\hline $\begin{array}{l}\text { - Paradigma del consenso (naturaliza } \\
\text { las diferencias y niega el conflicto). }\end{array}$ & $\begin{array}{l}\text { - Paradigma del conflicto (toma en } \\
\text { cuenta las relaciones sociales entre } \\
\text { clases y las disputas). }\end{array}$ \\
\hline
\end{tabular}

\section{Marco teórico}

Comum. \& Inf., v. 15, n.1, p. 46-65, jan./jun. 2012 


\subsection{La ficción, la mímesis}

La palabra "ficción" y sus derivados "figural/figurativo", proviene del verbo latino fingere que significa imaginar, crear, fingir, lo que implica que el registro ficcional se manifieste diferencial respecto de sus denotaciones, acciones, y el efecto de dicha acción.

Uno de los criterios que menciona Schaeffer para definir las practicas ficcionales como prácticas miméticas, es el criterio intencional-pragmático, es decir que todo acto mimético es selectivo en la medida en que obedece a una finalidad mimética. Dicha mimesis puede tener una finalidad simplemente funcional, cuando responde a una adaptación natural al medio, o intencional, cuando la selección mimética se dirige a la producción de semejanzas que "no existían antes del acto mimético y, por lo tanto, su existencia es causada por ese acto" (SCHAEFFER, 1999, p. 70). "Reconocer" semejanzas es un acto cognitivo, pero "producirlas" es un acto mimético, es decir, creador de sentidos ${ }^{3}$.

Otro criterio o subespecificación dentro del campo de las producciones imitativas se refiere a si la finalidad de la mimesis es "reinstanciar" lo imitado, es decir, obtener una realidad de la misma naturaleza que la imitada, o si se pretende "fingir" la realidad para obtener algo distinto de lo imitado. La diferencia tiene consecuencias ontológicas respecto de lo imitado: en la "reinstanciación" se busca imitar para "realizar" lo real imitado (copia o apariencia), el "fingimiento", en cambio, es un trabajo de mimesis que "irrealiza" lo real a los efectos de que sea reconocido y no se deje confundir con él.

Ciertos relatos acerca de la realidad sostienen su eficacia comunicacional sobre la contaminación de lo real y lo ficticio, manteniendo la incertidumbre respecto de los límites entre lo factual y lo ficticio. Frecuentemente, el narrador heterodiegético cuenta en tercera persona pero cede la palabra a un narrador homodiegético, de manera que el lector puede "ver" la escena registrada y al actor real convertido en personaje. El relato abunda en elementos referenciales que colaboran con la ilusión de desficcionalización. De manera que la estructura intencional original, constitutiva del marco pragmático de la producción/recepción ficcional, es ambigua.

\subsection{Conversión de lo factual en relato ficcional}

\footnotetext{
3 "cuando construyo un mimema, accedo al mismo tiempo a un conocimiento de lo que imito; en la medida en que la construcción de una imitación es selectiva en relación con las propiedades de la cosa imitada, es ipso facto un útil de inteligencia de esa cosa imitada (...) contrariamente a lo que sostenía Platón, la construcción de una imitación no es nunca un reflejo (pasivo) de la cosa imitada, sino la construcción de un modelo de esa cosa, fundado en la parrilla selectiva de similitudes entre imitación y cosa imitada" (Schaeffer, opus cit: 72).
}

Comum. \& Inf., v. 15, n.1, p. 46-65, jan./jun. 2012 
Para que el contenido factual - o real - se convierta en relato, deben realizarse una serie de procesos de transformación que reduzcan la infinitud de lo real en un sintagma narrativo delimitado por un principio y un fin. Dicha reducción resulta de una serie de selecciones que toma a su cargo un enunciador (narrador) desde cuya mirada y saber se relatan los hechos y se presentan los actores y su contexto de acción.

Por ello, en todo texto narrativo pueden distinguirse tres aspectos (GENETTE, 1972): la historia, conjunto de acciones, sucesos, lo que se cuenta; el relato, modo en que se cuenta la historia y la narración, acto narrativo por el cual un narrador asume la función de narrar esa historia a través de la materialidad del relato. Para el analista del discurso sólo es posible trabajar con la materialidad del relato ya que sólo el relato puede llevarnos a la reconstrucción de la historia y al estudio de su enunciación narrativa. Así, el relato se convierte en significante en el cual toma cuerpo el significado narrativo (FILINICH, 1997, p. 20).

El corpus de crónicas que analizamos se constituye así en relatos significantes con los que pretenden vehiculizar significados enmascarados en historias tomadas de la realidad. La tarea del analista del discurso consiste en relevar dichos significados y, en este caso particular, dar cuenta de los efectos que el nuevo registro narrativo tiene en la recepción y en la reformulación de representaciones sociales.

\subsection{El narrador: una mirada y un saber}

María Isabel Filinich define el punto de vista o perspectiva, desde la cual el narrador da cuenta de la historia, como una interacción entre sujeto y objeto $(1998,71)$. La autora retoma a Fontanille (1994) para caracterizar la noción de punto de vista, presente en la literatura: [...] la noción de punto de vista remite tanto a la posición de un sujeto como a la de un objeto: hay una operación de interacción en juego $[\ldots]$.

La aprehensión de un objeto es siempre imperfecta, y esta imperfección de la captación del objeto puede generar dos tipos de estrategias de parte del sujeto: o bien el sujeto recorre el objeto observado y retiene diversos aspectos para realizar una secuencia de puntos de vista; o bien el sujeto elige, mediante una operación de sinécdoque, un aspecto típico, y reorganiza todo el objeto alrededor 
de él. De cualquier manera, ambas estrategias presuponen la necesaria fragmentación del objeto de la percepción en partes. (FILINICH, 1998, 70-71).

Al ver, el narrador brinda al lector las características del objeto percibido de manera fragmentaria, siendo pues el lector el que deba reconstruir el objeto a partir de las partes: hay una [...] voluntad narrativa de construir un universo completo, aunque esa completud se sugiera mediante la construcción de universos fragmentarios" (FILINICH, 1998, 74).

Todorov (1991) considera que la mirada constituye distintos aspectos o tipos de percepción por medio de los cuales se evidencia la relación existente entre un él (de la historia) y un yo (del discurso), es decir, entre el personaje y el narrador. Considera tres tipos de percepción según sea una relación de mayor, igual o menor grado de saber respecto de lo que se narra, entre el personaje y el narrador:

Narrador > personaje (visión “por detrás”): típica del relato clásico en la que el narrador sabe todo, sus personajes no tienen secretos para él.

Narrador = personaje (visión “con"): el narrador sabe tanto como los personajes. Puede usar la primera persona o la tercera persona, pero siempre según la visión que de los acontecimientos tiene un mismo personaje.

Narrador < personaje (visión “desde afuera”): solo puede describir lo que se ve, oye, etc. porque sabe menos que los personajes.

\subsection{Polifonía}

Una de las formas de "reinstanciar" los sucesos, es decir, de crear la ilusión de "estar ahí" es la de hacer escuchar otras voces dentro de la narración. Por un lado, dicha inserción favorece la sensación de objetividad, pero, por otro, provee de una "representación" de lo factual constituida por elementos seleccionados por el narrador en función de la intención que guía toda ficcionalizaciòn.

Estos procedimientos de "citación", es decir, de dejar oír voces ajenas en el interior del propio relato (FILINICH, 1998, p. 46-48), pueden ser de tres tipos: el discurso directo, el discurso indirecto y el discurso indirecto libre (ANDERSON IMBERT, 1979). Puede afirmarse que la identificación del narrador con el personaje va en aumento, si se toma como punto de partida el discurso directo (mínima identificación) y como llegada el discurso indirecto libre (máxima identificación). Esta oposición es correlativa a la pareja telling / showing (narrar/mostrar), que plantea Henry James (1907; 1909). 


\subsection{Tiempo y espacio}

Las marcaciones que remiten a un tiempo y a un espacio exterior al discurso suelen conceder a la necesidad periodística de localizar la historia en el contexto cercano tanto espacial como temporalmente. Por eso, no faltan, en estas crónicas, las indicaciones como "En 1991...”; “El 31 de diciembre de 1999, a las seis de la mañana...", y las ubicaciones espaciales como "Las Heras es una ciudad del norte de la provincia de Santa Cruz, la más austral de la Patagonia argentina. Dos kilómetros la separan de Buenos Aires y ochocientos de la capital provincial, Río Gallegos, ....”.

En cuanto a las indicaciones cotextuales, ellas suelen ser más frecuentes en el relato ficcional, dado que en el interior de la diégesis construida, los sucesos y los actantes deben llevarse a cabo dentro de la lógica espacio-temporal que el discurso construye para ellos y cuyas coordenadas deben ser precisadas en el escenario y el tiempo de la ficción. Los espacios, en particular, no son elegidos por su posibilidad de ser puntualmente ubicados en la realidad sino porque puedan ser reconocidos por su universalidad por el lector, y vinculados a vivencias espaciales próximas a su mundo y las creencias colectivas. Así, cuando la cronista dice:

En el cuarto donde todo sucedió-debajo de la pintura blanca, de los banderines de fútbol, de los pósters de mujeres en bikini-, no quedan rastros de sangre..... ${ }^{4}$

Intenta recrear en el lector la imagen de un espacio que pertenece a su cotidianeidad y objetos y otros elementos descriptivos que se cuentan entre los esperables en el imaginario colectivo con la intención de describir a los personajes.

En otro tramo de la misma crónica, se lee:

En la puerta de entrada de la casa donde viven Alberto, su madre Nélida y su padrastro José, hay un póster: la imagen de la Biblia abierta, apoyada sobre un jarrón florido.

\footnotetext{
${ }^{4}$ Los ejemplos dados en este apartado Tiempo y espacio, pertenecen a la crónica "Los suicidas del fin del mundo", de Leila Guerriero, posteada el 16-9-2008.
}

Comum. \& Inf., v. 15, n.1, p. 46-65, jan./jun. 2012 
Otro aspecto a considerar, es el de las maneras de organizar el tiempo del relato con relación a la historia. Fillinich $(1998,50)$ reconoce dos modos: el orden lógico - cronológico de los acontecimientos (argumento) y el orden en que estos son expuestos en la narración (trama).

Algunas maneras de alterar el orden lógico, o anacronías (GENETTE, 1972), son la analepsis o retrospección, y la prolepsis o anticipación, menos común.

Respecto de la duración, se refiere a todo tipo de anisocronías que sirven para acelerar o ralentizar el ritmo del relato: "la pausa (la historia se detiene mediante una descripción, por ejemplo); la escena (suerte de equivalencia entre la supuesta duración temporal del diálogo y el espacio que el texto le asigna); el sumario (un largo período de tiempo condensado en un espacio breve de texto) y la elipsis (sucesos significativos presupuestos en la historia que el texto omite)" (FILINICH, 1998, p. 51$52)$.

Finalmente, la frecuencia en que aparece una historia relatada, puede presentar un relato de tipo singulativo (un acontecimiento sucede una vez y se lo narra una sola vez), anafórico (tantas veces como sucede un acontecimiento, se lo narra), repetitivo (sucede una vez y se lo narra varias veces) o iterativo (varias veces sucede y se lo narra una sola vez) (FILINICH, 1998, 52-53).

\section{Análisis del corpus textual}

\subsection{El enunciador narrativo}

En los relatos que constituyen estas crónicas, el narrador no trata de borrar sus huellas como en la crónica tradicional, sino que emerge, mediante procedimientos lingüísticos diversos, en la superficie del discurso. Aún cuando recurra a procedimientos de "invisibilización" a los efectos de disfrazar su relato de historia, no duda en dejar marcas de su presencia.

Puede aparecer de manera (a) implícita o (b) focalizada:

(a) Antes de esta visita clandestina, pude ver a Silvina sólo una vez, durante diez minutos ${ }^{5}$

(b) Me contaron que existe un barrio de mujeres solas y, ahora que empecé a buscarlo, veo que la mujer más sola soy yo. ${ }^{6}$

\footnotetext{
5 "Pollita en fuga: Silvina, de 15 años habla desde la clandestinidad", por J. Licitra. No 64 de Rolling Stone

6 "El barrio de las mujeres solas", 30-5-2010
} 
En (a) la primera persona le permite colocarse en el lugar del testigo que conoce o conoció a la protagonista de la historia. En (b), en cambio, el grado de implicación es mayor pues se involucra en la historia como un personaje más, o, al menos, como quien recoge lo narrado para lograr un aprendizaje o introspección sobre sí misma.

Estos modos de hacerse presente, acentuados por el uso de la primera persona, sugieren un grado de implicación respecto de lo que narran que no sólo habilita la introducción de la subjetividad y, por lo tanto, del predominio de la dimensión pathémica sobre la lógica- sino que, además, instituye un narratario (lector ideal) con el que busca establecer un vínculo de com-padecimiento, es decir "sentir-con", a través de la explicitación de sentimientos, y del estado emocional que le provoca lo narrado. El narrador habla de sus propias impresiones, describe dando cuenta de su percepción del mundo exterior y de lo que dichas percepciones le provocan:

El ascensor es de un metal despintado, es angosto, es demasiado, todo acá es angosto, pienso, y pienso en las celdas, los barrotes, las colillas, ese mate, los borcegos, quiero irme. ${ }^{7}$

Greimas (1973-1966-:13) considera la percepción como “el lugar no lingüístico en que se sitúa la aprehensión de la significación". Es decir, que esa mediación sensorial del sujeto respecto del objeto de su percepción deja su huella en la constitución de la significación. En la cita puede verse cuáles son los objetos que su percepción selecciona y retiene de aquel lugar (el Establecimientos Inchausti) donde la cronista dice haber conocido personalmente a Silvina. Son partes de un todo, es una realidad constituida por fragmentos que se convierten en significados, signos que orientan una interpretación.

La sensación predominante en estas crónicas es la ambigüedad, la falta de correspondencia entre lo que se muestra y lo que termina develándose:

Al lado de Chatràn [un gato] hay tres celadoras en estado de sopor. Toman mate dulce y se dejan cebar por un hombre de seguridad. Hay un contraste entre el gesto

amable del cebador, y el brillo amenazante de sus borceguíes negros, brutales, recién lustrados. El tipo me ofrece un mate, no dejo de mirarle los pies.

Así como los gestos de amabilidad son invalidados por sus borcegos negros del hombre de seguridad, todo en estas crónicas parece mostrar algo que no es. El narrador se empeña en advertir

7 "Pollita en fuga: Silvina, de 15 años habla desde la clandestinidad", op.cit.

Comum. \& Inf., v. 15, n.1, p. 46-65, jan./jun. 2012 
sobre la necesidad de "desconfiar" de las apariencias, de saber y ver más allá de los preconceptos y de las primeras impresiones. Y estas crónicas se proponen tal develamiento.

La referencia a marcas de zapatilla y de productos estéticos, que presupone conocidos por su narratario/a, colabora con la construcción de esa ambigüedad entre lo que parece y lo que es:

$>$ Me pregunto si Koleston habrá sacado una línea 'negro celador' porque el color es sencillamente único

Sin joyas y sin Nike, Silvina se desequilibra. ${ }^{8}$

Igual función parecen tener las referencias intertextuales al cine y la literatura:

(1) Empiezo a comer el guiso con una masticación extraña: como si me estuviera tragando a Bambi.

(2) La mujer habla con la voz rítmica y baja, como si en realidad rezara, y la escena recuerda a esos momentos de sórdida tranquilidad que se imagina el cineasta Arturo Ripstein cuando tiene ganas de imaginar cosas feas (es decir, casi siempre).

(3) Luis se retiró con modales de paje real, y se encomendó al santo de turno para no terminar preso.

Pero Silvina escuchó todo.

Se acercó despacio, con una serenidad de western. ${ }^{9}$

Las comparaciones con la literatura y el cine suponen un narratario con el mismo grado de saber que la enunciadora, la que, por otra parte, se caracteriza como perteneciente a una clase cuyo capital cultural y simbólico la legitima para realizar un análisis o una interpretación autorizada. Por otra parte, dichas alusiones no están exentas de la intención de mostrar la dimensión ilusoria, como de "fachada que debe ser derribada" que presenta el fenómeno del que la crónica se propone dar cuenta. Es decir, personajes como "Bambi" o el "paje real" son tan ilusorios como las ficciones de las que el cine ("Ripstein", "western") da cuenta.

8 Los ejemplos pertenecen a la crónica "Pollita en fuga...." citada en notas al pie anteriores.

9 Los ejemplos pertenecen a "El barrio de las mujeres solas", de Josefina Licitra, posteada el 30-5-2010.

Comum. \& Inf., v. 15, n.1, p. 46-65, jan./jun. 2012 
Es interesante, también, analizar los casos en que la presencia del/a narrador/a se presenta "focalizada", es decir, cuando toma parte dentro de la historia. En el caso de "El barrio de las mujeres solas", la cronista se semiotiza como narradora y se explicita al comienzo del relato adoptando un rol no sólo de testigo sino también de "héroe", en el sentido clásico: se entera de que existe un barrio de mujeres solas y decide viajar para descubrirlo y conocerlo; dicho saber la diferencia del resto de los mortales a quienes deberá comunicarlo.

Para ello, primeramente debe configurarse como un personaje más pero con mayor jerarquía que el resto de los personajes de la historia. Su superioridad está dada por su capital cultural y su procedencia social. Dicha legitimación proviene:

a- de sus saberes previos: A raíz del nombre de una de las hijas de Celina Ramos, Eudosia, la narradora intercala:

$>$ Eudoxia, en griego, significa “buena reputación”. Me acuerdo de esa estupidez mientras Celina Ramos cuenta su historia en oraciones cortas.

b- de su procedencia social:

- Hoy es San Expedito, el santo de la velocidad. En la puerta de la iglesia, Emilia Mamaní se prepara junto a veinte personas para caminar dieciocho kilómetros por un desierto rocoso. Pienso en acompañarla (en auto) y voy a la despensa a comprar agua mineral.

-¿Tiene agua?

Del otro lado del mostrador, alguien toma una botella de Sprite vacía, la llena con agua del grifo, $y$ me la da.

La narradora se incorpora a la diégesis a la manera del mito clásico del viaje iniciático del héroe:

1-misterio por descubrir y conocer

2-decisiòn de emprender el viaje

3-dificultades diversas caracterizan el trayecto

4-necesidad de un guía para llegar al conocimiento

5-conocimiento transmitido por diversos personajes

6-regreso con un saber adquirido

Comum. \& Inf., v. 15, n.1, p. 46-65, jan./jun. 2012 


\section{1- Misterio por descubrir:}

Me contaron que existe un barrio de mujeres solas, ..........

> La historia empezó en marzo de 2007, cuando el fotógrafo Ariel Pacheco me escribió desde Catamarca, una provincia en el norte argentino, para contarme que sabía de alguien que, una vez, escuchó una historia que quizá fuera un mito: había, en algún rincón de Catamarca, un barrio sin hombres.

\section{2-Decisiòn de emprender el viaje:}

$>$ Tal vez el lugar fuera un fiasco, pero decidí viajar.

$>$ Un mundo sin hombres era, como mínimo, una promesa para tener en cuenta cuando llegaran las vacaciones.

\section{3- Dificultades que caracterizan el trayecto:}

$>$ En Internet decía que en esa zona había vicuñas, petroglifos y volcanes, que Antofagasta significaba "casa del sol" y que llegar hasta el sol era = como es lógico = complejo: había que viajar a San Fernando del Valle, la capital de Catamarca, y luego hacer doce horas de trayecto en camioneta.

> El viaje desde la capital, San Fernando, es trabajoso y lerdo, y puede hacerse de dos formas: Los antogasteños usan El antofagasteño, un autobús que cubre el trayecto en veintidós horas y ofrece ese tipo de servicios que un turista americano tildaría de "folclóricos": los neumáticos se pinchan, las gallinas picotean los asientos, y algunos pasajeros honran las curvas del camino con un desparramo de vómito. La otra alternativa es ir en camioneta: en ese caso son doce horas de polvo, traqueteo y piedras; y la sensación intransferible de no estar avanzando sobre ruedas, sino a patadas en el trasero.

$>$ La llegada al lugar de destino se complica aún más porque algunas lugareñas le advierten que el teléfono generalmente no funciona y que sólo existe un aparato telefónico para el que hay que hacer cola si quiere usarlo.

\section{4- Necesidad de guía:}

Aníbal Vázquez, un guía de montaña, dirá horas más tarde que la migración......

A partir de la introducción del nombre del guía, la enunciadora usará la $1^{a}$ persona plural, es decir, incluye a su acompañante, el fotógrafo, Ariel Pacheco: 
Nos aloja en su casa una de las pocas personas con ganas de hablar. Se llama Pascuala Vázquez......

Desde aquí en adelante, la enunciadora introducirá la voz (testimonio) de diferentes mujeres habitantes del pueblo quienes relatan distintas historias de sí mismas y de otras moradoras. La sensación de verosimilitud respecto de la escena es acentuada porque se conserva el registro oral, y la narradora introduce su pensamiento tal como si lo estuviera viviendo (discurso indirecto libre):

Luego sigue hablando de mujeres, niños y jueves, pero ya no hay mucho más que oír. Nunca comí llama. Pacheco tomó una foto de una llama en el camino y el bicho era de veras lindo. $\{. .$.$\} La voz de Pascuala sigue: dice que ella no vive en el barrio San Juan (su casa está a tres$ cuadras de allí) pero que igual crió sola a sus hijos.

\section{5- Conocimiento transmitido por distintos personajes:}

Los datos acerca del pueblo de mujeres solas no son solamente suministrados por ellas. La narradora introduce testimonios de voces masculinas autorizadas: Evaristo Alejandro Acevedo, intendente de Antofagasta, quien, a su vez, cita indirectamente al intendente anterior, Luis Eduardo Rodríguez. La historia que narra el funcionario es referida de manera indirecta por la narradora.

Cuenta entonces que el barrio de mujeres solas se creó en la gestión anterior, por motivos que se alejan bastante de las teorías sociales y la conciencia feminista.

$>$ En San Juan nació como respuesta a un problema difícil y común. En las zonas extremadamente rurales del norte argentino = como Antofagasta de la Sierra = siempre fue usual que las mujeres se embarazaran de hombres a los que habían visto muy pocas veces en su vida. $\{\ldots\}$

$>$ El barrio de mujeres solas, entonces, no nació bajo el impulso de ninguna lesbiana militante: surgió como un intento del Estado por dar una vivienda $=$ un mínimo amparo $=$ a un puñado de madres que no tenían un techo bajo el que caerse muertas.

Luego vendrán las historias personales de Celina Ramos a quien la cronista presentará en el escenario de su casa, y les dará voz en forma directa:

> La casita de Celina Ramos tiene dos dormitorios y un baño que no se parecen, en ningún caso, a dos dormitorios y un baño: el lugar es un receptáculo ciego, un vacío espectral al que Celina llegó hace un año junto a dos hijas, la Olga y la Eudosia, que ya le dieron dos nietos. 
Puede verse que dentro de la palabra de la narradora (que da cuenta a lo largo del relato de su nivel cultural superior al de las mujeres que entrevista) aparece el registro ideolectal de las entrevistadas (artículo delante del nombre propio).

Inmediatamente, la enunciadora principal introduce el discurso directo de Lucía:

- Me los reconocieron a todos salvo a éste, que es natural - explica Lucía, y apoya la mano sobre la cabeza del niño. Se la ve orgullosa. El niño calla porque no entiende nada, o porque entiende todo.

De igual modo la inclusión del testimonio de Emilia Mamaní servirá para remitir a otra mujer, Carina:

-Me molestó la intervención del fiscal, porque por más leyes que haiga....que yo tengo mi hijo, que lo pongo en el juez, que el padre me pasa el dinero, eso no soluciona el problema - explica Mamaní-. Muchas mujeres se llenan de chicos para ir a cobrar la cuota. Porque podés tener un hijo por error, máximo dos, pero no seis, como la Carina. ¿Usté vio la Carina?

\section{6- Regreso con un saber adquirido:}

La narradora termina su crónica con una secuencia expositiva explicativa en la que desarrolla el concepto de "matriarcado" en sus dos acepciones de matrilinealidad y matrilocalidad.

No obstante, toda esta explicación en la que da cuenta de sus conocimientos resulta aleatoria para el caso del barrio de San Juan pues no se trata de un matriarcado sino de un lugar en el que se refugian y reúnen mujeres que han sido víctimas del desamparo, de la carencia de educación, del sometimiento. Dependen indignamente del Estado y de los hombres, y no tienen autonomía más que para criar a sus hijos, que las acompañan como "carga".

Como menciona Schaeffer, el final de la crónica reconfirma esa disociación entre los esquemas representacionales a los que recurre el discurso narrativo y el catálogo de creencias compartidas en relación a la noción de "matriarcado". Este principio, característico de la ficción, orienta los efectos de sentido en una dirección diferente que los instituidos por la prensa masiva. Reorienta la lectura y obliga a repensar los imaginarios instituidos mediante una puesta en escena que compromete éticamente al receptor.

Comum. \& Inf., v. 15, n.1, p. 46-65, jan./jun. 2012 
Sin embargo, la sensación que cierra la crónica es la de mujeres que no están solas. Por el contrario, están rodeadas de niños y pasan la vida trabajando. Las tareas domésticas y la maternidad “infinita” las hace más “mujeres”, las reconfirma en su identidad.

\subsection{El tiempo y el espacio}

En la crónica "Un día en la vida de pepita la Pistolera" $"$, el título alude a una duración temporal que el texto no reproduce, o, por lo menos, designa la duración aparente de una posible entrevista de la que se releva la información que nutrirá la crónica. Así, "un día” no es más que una metonimia de toda la vida de la protagonista (objeto de la crónica), que se reconstruirá mediante analepsis, es decir, partiendo del presente de la crónica hacia el pasado, cuando apenas era una niña "adiestrada" por su padre como un varón.

El tiempo es manipulado por la narración de manera que lleva al lector del presente al pasado y del pasado al presente de manera constante, lo que obliga a repensar siempre la escena presente en función de las experiencias pasadas. Así, la violencia de Pepita es abordada desde una historia que debe ser conocida y reconstruida para entender su conducta y com-padecer su suerte.

En esta ida y vuelta temporal, lo que el cronista "ve" hoy es desmentido por lo que sucedió en el pasado, de manera que todo lo que aparece ante la vista del narrador testigo presenta siempre una naturaleza ambigua que convoca al lector a sentimientos dobles, contradictorios.

La crónica comienza con una escena en la que Margarita (Pepita) cuida a su padre de 83 años y lo asiste en el momento del sueño y el descanso. La figura de un anciano que es asistido por su hija convoca a un sentimiento de ternura, piedad, comprensión por parte del lector:

> - "Está bien, papá, dormí, dormi”, le dice Margarita Di Tulio a un hombre de 83 años que se pasea en calzoncillos y balbucea: Es Antonio Di Tulio, el hombre que la inició en la guerra, el que no tuvo un primogénito varón pero crió una hija con una fuerza descomunal,......

A continuación el narrador enumera una serie de acciones llevadas a cabo por ese anciano débil y aparentemente inofensivo a los 83 años, marcadas por el autoritarismo, la violencia, la insensibilidad:

$>$...el que (el padre) comenzó a entrenarla luchando con ella como un borrego, el que la obligó a competir con varones más grandes en peleas callejeras desde los dos años. El mismo que

\footnotetext{
${ }^{10}$ Posteada el 24 de octubre 2009, de Cristian Alarcón, Página 12, Perfil.
} 
después, cuando no soportó la rebeldía de su hija de 16 años, le quebró la nariz. El mismo que la perdió de vista cuando ella decidió competir a lo grande, y ganar dinero y batalla contra hombres.

Esta disonancia entre el hoy y el pasado, entre lo que el cronista ve y lo que ha podido reconstruir, entre el ver y el saber, instala la ambigüedad que recorrerá toda la crónica y que sintetiza al finalizar este primer párrafo:

El mismo anciano que hoy duerme tranquilo, como un niño acariciado por las manos llenas de nicotina, de piel suave pero fuertes como herraduras, terminadas en uñas largas, rojas, sutiles garras de una leona reina de la selva clandestina. Las manos de Pepita la Pistolera.

La descripción recurre a un campo semántico que se presenta no sólo ambiguo sino también contradictorio (caricias/nicotina; suave/fuerte; sutileza/garra). Este comienzo, que inaugura la alteración de la lógica temporal lineal mencionada, introduce la clave de lectura con la que pretende orientar la interpretación: alteración de la continuidad temporal que produce también alteración o imprecisión de los límites entre lo que es ser varón y ser mujer; entre la relación entre un padre y una hija.

Las analepsis son frecuentes, sobre todo cuando estas crónicas buscan reconstruir, a partir de la situación presente, toda una historia con la que elaborar nuevos recorridos interpretativos acerca de fenómenos sociales silenciados por la prensa hegemónica.

Pueden encontrarse prolepsis, cuando se busca anticipar algún comentario que puede ser pertinente para lo que se está narrando. En "El barrio de las mujeres solas", la cronista anticipa algunos dichos que se darán a posteriori en las entrevistas. Dicho procedimiento no sólo da cuenta de un proceso de selección intencional sino también de alejamiento de la rutina de desgrabación en el periodismo tradicional:

$>$ Aníbal Vázquez, un guía de montaña, dirá horas más tarde que la migración también se dio por comodidad geográfica.

En cuanto a la reconstrucción del espacio, el narrador introduce descripciones del espacio y el momento, que no tienen como finalidad ubicar la acción sino como telón de fondo que pasa a primer plano para reforzar la sensación de soledad y ambigüedad que atraviesa la historia: 
Sobre el horizonte del puerto, tras las fábricas de harina de pescado que tapan las narices de mal olor, caen las últimas gotas de sol, y un cielo rosado y pálido le da paso a la noche. Margarita brilla sinuosa, bebe champagne, se agita, se lleva la mano al pecho, como desbordada, y a cada ronca frase que pasa, desnuda su alma, como, según jura, nunca hizo con su cuerpo ante un hombre que no ame.

$\{\ldots\}$

Margarita cruza la puerta (de un bar de copas) en unos pantalones a cuadros chicos y de un verde fluorescente. Pisa sobre zapatillas negras plastificadas al charol, con dos centímetros de plataforma, y arriba lleva un buzo de mangas cortas.

La nocturnidad, los espacios marginales, el abandono son elementos más asociados al hombre que a la mujer, pues se relacionan con la fortaleza de temperamento y no con la debilidad femenina. A estos espacios pertenece Pepita (Margarita), en los que se mueve con naturalidad. Una frase que inaugura uno de los párrafos es significativa respecto de la ambigüedad que reviste a este personaje, su carencia de origen, de identidad y, a la vez, el absurdo que atraviesa sus sentimientos, mitad masculinos y mitad femeninos:

$>$ Después de la guerra, Margarita prefiere la seguridad de sus cabarets.

\section{Conclusiones}

Las crónicas que hemos analizado pretenden dar cuenta de una realidad que aparece ausente en el escenario del periodismo hegemónico. Puesto que los hechos se presentan traspuestos en palabras y en forma de relato adquieren "realidad". Los procesos de ficcionalización a los que son sometidos los acontecimientos "registrados" del entorno inmediato o mediato al que accede el cronista construyen un contrato con el lector en el que la "incredulidad" es suspendida y se asiste a la ilusión de realidad que trae aparejada toda forma narrativa.

Dicha redescripción del mundo mediante la ficción es la representación de una ausencia que se vuelve presente mediante el relato. La representación de lo ausente consiste en operaciones que permiten leer algo del orden de lo mismo, de la alteridad y de la analogía. La realidad es entonces, resultado de un proceso, poiesis o invención por el cual se constituye en objeto. El referente "real" cobra existencia como representación, es decir como capacidad de interpretación y no como acceso 
inmediato y directo a él. La ficción, en tanto mímesis, convoca a la puesta en escena de lo esencial, del núcleo efectivo de la acción.

Por otra parte, respecto de final que presenta toda historia, nos hallamos frente a historias sin final o, en todo caso, con un final que advierte acerca de una realidad cuya continuidad aparece como no resuelta. El cronista, en todo caso, ha cumplido la función de "dar a saber" y, por lo tanto, "dar existencia" a una realidad sobre la cual no puede intervenir más que como observador, registrador externo y funcionar como "puente" entre ella y el lector. Este procedimiento es complementario a la dimensión ambigua con la que se inscriben datos, objetos, personas, comportamientos. Se trata de crónicas que refieren una realidad sin certezas, o, en todo caso, una crisis de las creencias instituidas a los efectos de repensar los nuevos (o viejos) fenómenos de la pobreza y la marginalidad, ausentes de la agenda del periodismo hegemónico.

En este sentido, autores como Mónica Bernabé (2006) consideran que el primer aspecto que distinguiría a la nueva crónica latinoamericana sería, más que la intención por contar historias, su empeño por encontrar una voz en confluencia con una mirada como estrategia de percepción de un mundo cada vez más complejo.

Detrás de estas crónicas, ya no vemos entonces al escritor comprometido o al intelectual revolucionario. Tampoco el contexto social es el mismo que en las décadas del 60 y el 70. Como bien señala Bernabé, desde el momento en que la alianza entre las vanguardias estéticas y políticas comenzó a desarticularse, y cuando las narrativas abandonaron el relato de la utopía por efecto de la persecución impuesta por las dictaduras latinoamericanas, las ideas neoliberales empezaron a invadir progresivamente todos los espacios.

Y muchas de las crónicas que ahora leemos están indisolublemente ligadas a la crisis y la transformación neoliberal de las economías y las sociedades latinoamericanas (POBLETE, 2009). De allí la potencialidad que ofrece este género como material de análisis social y cultural.

Son historias que suelen girar en torno a la desolación, el desencanto, la marginación, la violencia y la injusticia o, directamente, proponen una fuga hacia el universo de lo desacostumbrado ${ }^{11}$.

\footnotetext{
${ }^{11}$ Como lo ejemplifica Manuel Vicuña al describir el repertorio de crónicas de Leila Guerriero, una de las autoras emblemáticas de este género: "Un gigante que es una ruina de sí mismo habitada por sus recuerdos de gloria; una joven violada que apuñaló a la criatura al momento de parirla, en un arrebato psicótico; un mago manco cuya única mano esgrime la baraja con un virtuosismo desafiante; unos jóvenes varados en el limbo de la Patagonia, que parecen practicar el suicidio
} 
Por ello, en este nuevo escenario del capitalismo postindustrial, las crónicas muchas veces llegan a constituir un acto de intervención, en un sentido performativo, una operación de interpelación ética que actúa e intercede para que se produzca el encuentro entre el lector y aquello que permanece invisible a primera vista o aquello que no se quiere ver (Bernabé, 2006).

\section{Referencias}

ANDERSON IMBERT, E. Teoría y técnica del cuento. Buenos Aires: Marymar, 1979.

BERNABÉ, M.; CRISTOFF, María Sonia (Comp.). Prólogo: a Idea Crónica. Rosario: Beatriz Viterbo, 2006.

ECO, U. Seis paseos por los bosques narrativos. Barcelona: Lumen, 1996.

FILINICH, M.I. Enunciación. Buenos Aires: Eudeba, 1998.

FONTANILLE, J. El giro modal en semiótica. Buenos Aires: Morphé 9/10, 1994.

GENETTE, G. Figures III. París: Seuil, 1972.

ISER, W. La ficcionalizacion: dimensión antropológica de las ficciones literarias. En: . et al.

Teorías de la ficción literaria. Madrid: Arco Libros S.L, 1997.

METZ, CH. Ensayos sobre la significación en el cine. Buenos Aires: Tiempo contemporáneo, 1972. POBLETE, Juan. Crónica, ciudadanía y representación juvenil. En: LEMEBEL, Pedro. Nuevo Texto Crítico. v. 22. Barcelona: Paidós, 2009.

RICOEUR, P. Historia y narratividad. Barcelona: Paidós, 1999.

como un recóndito sacramento colectivo; un baterista down ungido líder espiritual de una banda rock en constante trance creativo; unas mujeres que hicieron de la venta de cosméticos una liturgia del capitalismo como fórmula de la felicidad y de la prosperidad individual; o una antropóloga forense que aprendió a descifrar, en los huesos desperdigados en las fosas comunes, el lenguaje del terrorismo de Estado y la identidad perdida de sus víctimas". 